\title{
Fabrication of Dye Sensitized Solar Cell Based on Titanium Dioxide $\left(\mathrm{TiO}_{2}\right)$
}

\author{
Ari A. Mohammed, Alan S. Said Ahmad, Wafaa A. Azeez \\ Department of Physics, Faculty of Science, University of Zakho, Duhok, Iraq \\ Email: alho.amedi@yahoo.com
}

Received 16 July 2015; accepted 1 September 2015; published 4 September 2015

Copyright (C) 2015 by authors and Scientific Research Publishing Inc.

This work is licensed under the Creative Commons Attribution International License (CC BY). http://creativecommons.org/licenses/by/4.0/

(c) †

\section{Abstract}

The Dye Sensitized Solar Cell (DSSC) plays an important role because of low material cost, ease of production and high conversion efficiency as compared to other thin-film solar cell technologies. The main objective is to create and find the best configuration of the solar cell based on materials that are inexpensive and highly efficient in solar energy conversion and subsequently test the efficiency of dye sensitized titanium dioxide solar cell. We begin the process with two glass plates coated with Fluorine tin oxide (FTO). Titanium dioxide is applied to the conductive side of one plate and the other plate is coated with graphite. A dye is adsorbed on to the $\mathrm{TiO}_{2}$ layer and then the plates are sandwiched together. A drop of iodide electrolyte is then added between the plates. The tests carried out indoors under a lamp emitting all wavelengths in the visible spectrum were not found to provide consistent data due to substantial heating of the cell. The outdoor tests carried out in natural sunlight exhibited steady voltage at much higher level. Future research will involve the incorporation of quantum dots instead of the organic dye as a sensitizer. Quantum dots have the advantages of providing tunable band gaps and the ability to absorb specific wavelength.

\section{Keywords}

Transparent Conducting Glass, Titanium Dioxide $\left(\mathrm{TIO}_{2}\right)$ Nanoparticles, Organic Dyes, Electrolyte

\section{Introduction}

The Dye sensitized solar cell (DSSC) is one of the huge and economic challenges in the $21^{\text {st }}$ century. The main objective is to create and find the best configuration of the solar cell based on materials that are inexpensive and highly efficient in solar energy conversion and subsequently test the efficiency of dye sensitized titanium dioxide solar cell. The DSSC has reported high efficiency cells based on Titanium dioxide $\left(\mathrm{TiO}_{2}\right)$ Nanoparticles and transparent conducting glass, natural dyes and iodine electrolyte solutions. The DSSC separates the two requirements as the charge generation is done at the semiconductor dye interface and the charge transport is done 
by the semiconductor and the electrolyte that is spectral properties optimization can be done by modifying the dye alone, while carries transport properties can be improved by optimizing the semiconductor and the electrolyte composition. Solar cell with high efficiency and low cost is necessary for sunlight capture and the conversion of light to energy [1].

\subsection{Fundamental Parts of Dye Sensitized Solar Cell}

There are a set of five different layers of components stacked in serial, including glass substrate, transparent conducting glass, Titanium dioxide $\mathrm{TiO}_{2}$ nanoparticles, organic dyes, electrolyte solution, and counter electrode is presented in Figure 1.

A typical cell structure is explained. In five different components:

1) Transparent Conducting Glass:

2) Titanium Dioxide $\left(\mathrm{TiO}_{2}\right)$ Nanoparticles:

3) Dyes:

4) Electrolyte:

5) Counter Electrode:

First there is a layer In the front of the cell of glass substrate, this layer allows sunlight penetrating into the cell while conducting electron carriers to outer circuit is called Transparent conducting oxide. Second a layer of negatively doped $\mathrm{TiO}_{2}$ nanoparticles is used. The beneficial of $\mathrm{TiO}_{2}$ include high photosensitivity, high structure stability under solar irradiation and low cost [2]. Third the sensitivity of dye molecules are the key component of a DSSC to have an increased efficiency through their abilities to absorb visible light photons [1]. Organic dyes, including natural pigments and synthetic organic dyes, have a donor acceptor structure called as push-pull architecture, thus improving short circuit current density by improving the absorption in red and infrared region. Natural pigments, like chlorophyll, carotene, and anthocyanin, are freely available in plant leaves, flowers, and fruits and fulfill these requirements. Experimentally, natural dye sensitized $\mathrm{TiO}_{2}$ solar cells have reached an efficiency of $7.1 \%$ and high stability [3]-[5]. There are three different kinds of electrolytes have been used in DSSCs: 1) the most common electrolyte is $\mathrm{I}^{-} / \mathrm{I}_{3}^{-}$in organic solvents, such as acetonitrile; 2) inorganic ionic liquids made of salts or salt mixture; 3 ) solid electrolyte [6]. On the back of the DSSC there presents another glass substrate covered with a thin layer to regenerate $\mathrm{I}^{-}$and as the cathode material [7]. Conducting polymers can also be used. Polyaniline film on stainless steel by electrochemical polymerization bas been reported as a counter electrode of DSSC. It is cheap and non-fragile [8].

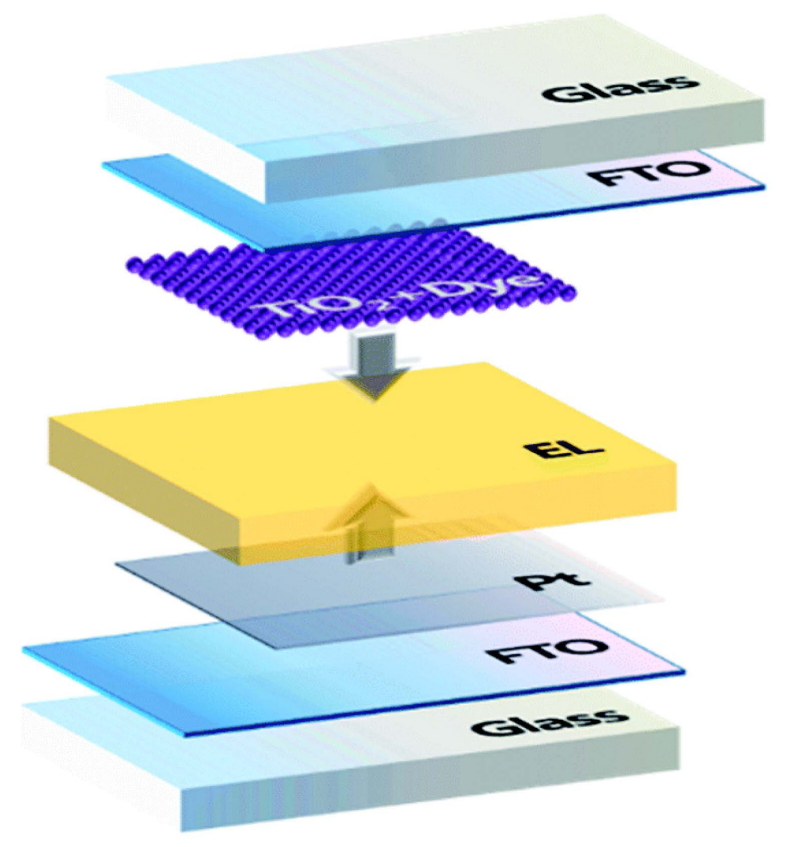

Figure 1. Structure of a DSSC. 


\subsection{The Mechanism of Structure and Power Generation}

The main idea and the mechanism of DSSC is quite obvious, photon of different energy in sunlight strike on the cell. Figure 2 shows the structure of DSSC consist of a substrate with a transparent electrode, titanium dioxide (TiO2) nano-particle layer formed over it, natural dye, an electrolyte solution and counter electrode substrate. Mostly an electrolyte solution containing pure Iodine, Potassium Iodide and Ethylene glycol. The power generation mechanism of DSSC is described as follow. Light strike into a cell Photo-excitation of an electron from the HOMO of the dye to the LUMO is followed by charge transfer into the conduction band of the titanium dioxide. Electrons then flow out of the $\mathrm{TiO}_{2}$ from the anode and the circuit is completed through the external load, supplying power. The oxidized dye needs to be regenerated, and hence an electrolyte layer is necessary. On the counter electrode, electrons are injected into the electrolyte and reduce $\mathrm{I}_{3}^{-}$ions to $\mathrm{I}^{-}$ions (when an iodine electrolyte is used). $\mathrm{I}^{-}$ions diffuse in the solution, reach the dye, give up electrons, and are oxidized forming $\mathrm{I}_{3}^{-}$ ions. This cycle is repeated causing power generation by light irradiation [9].

\section{Experimental Works}

\subsection{Constructing the Cell}

We begin the process of creating the solar cells with two glass plates coated with Fluorine Tin Oxide (FTO). This thin semiconducting layer allows charge to flow since glass in itself is nonconductive. The plates are first tested to find the conductive side of the glass. This conductive side will be covered with the other materials. Titanium Dioxide is applied to the conductive side of one plate by using a glass rod and rolling it on the plate until a neat coating is achieved. (Note: to keep the cells in place, it is important to place a piece of tape on the left and right sides of the plate so that the plate will not be moving around as shown in Figure 3. The tape is overlapping on the top also allowing for uniform thickness of the $\mathrm{TiO}_{2}$ film as the $\mathrm{TiO}_{2}$ paste will only fill into the space below the tape, when the glass rod is rolled over). A similar piece of glass should also be placed directly in contact (at the bottom) with the plate so that the titanium dioxide paste may have a neat coating to the edge.

This plate is then placed above a Bunsen burner for about 30 minutes so that the $\mathrm{TiO}_{2}$ is bonded to the plate. This process is called sintering and allows a three dimensional network to be achieved so that electron flow may occur. Following the sintering process, the plate is allowed to cool and is then placed in a bath of the dye Strawberries solution for 30 minutes as shown in Figure 4. This is where the importance of the $\mathrm{TiO}_{2}$ nanopar-

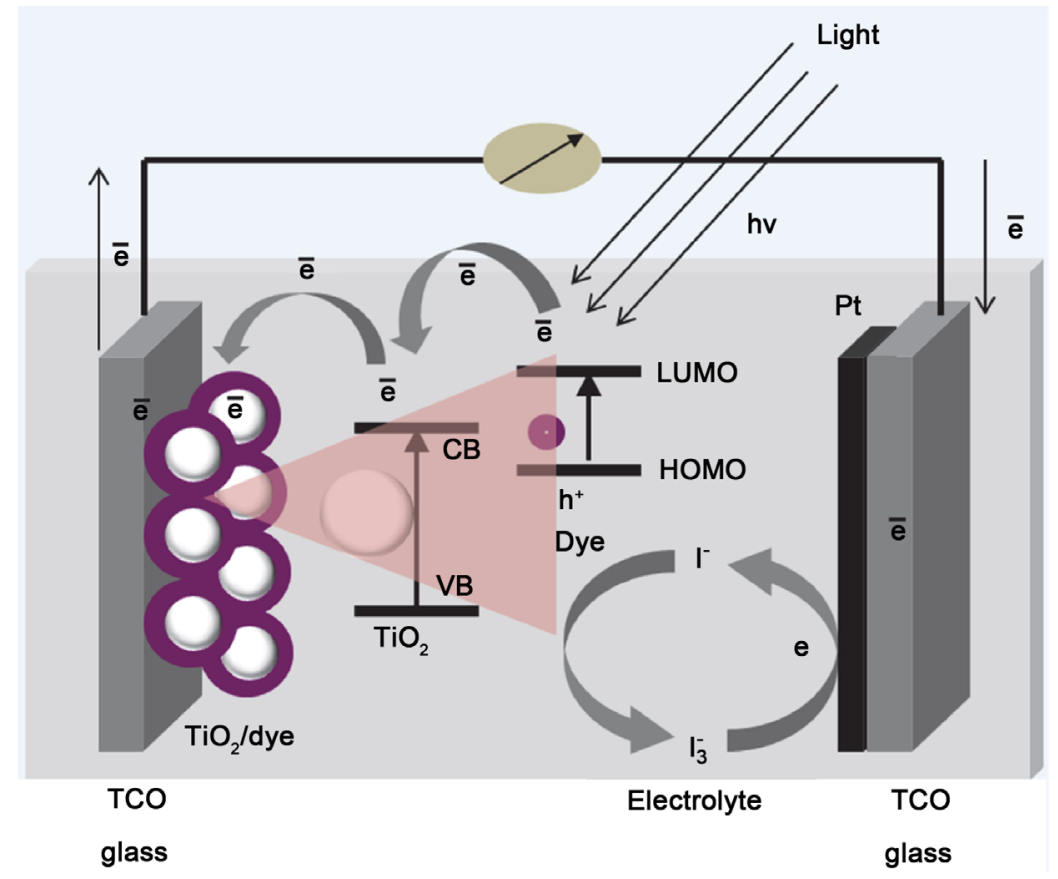

Figure 2. Schematic diagram of dye sensitized solar cell under light illumination. 


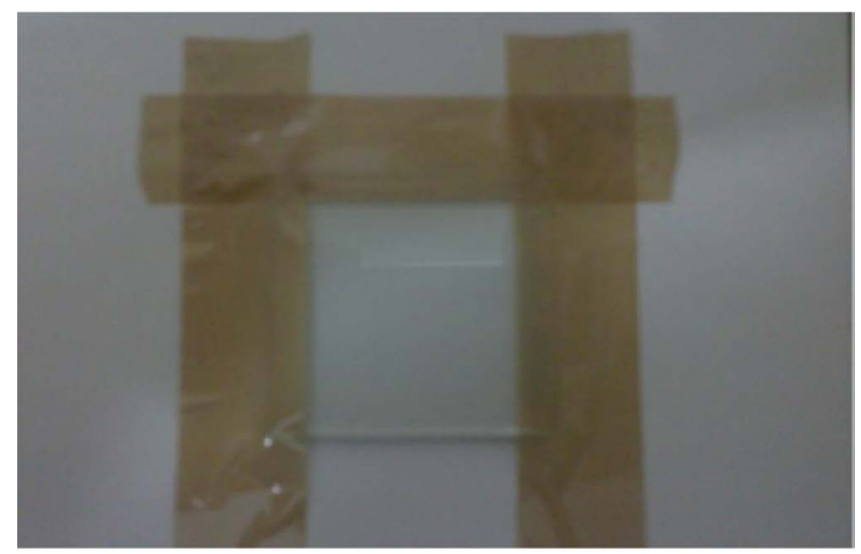

Figure 3. A glass plate tape on the three sides about $0.5 \mathrm{~cm}$.

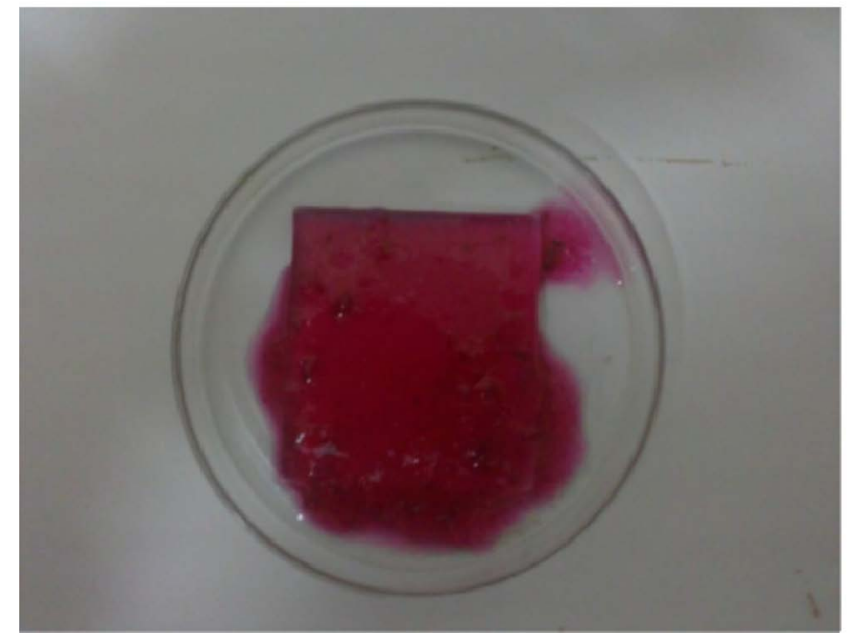

Figure 4. Cell is immersed in the strawberry juice.

ticles comes into play. The increased surface area allows for a greater amount of dye molecules to be absorbed, which will be of great importance during the test. The amounts of electrons allowed to flow through the system are dependent upon the number of dye molecules present in the cells themselves. The greater surface area translates to an increased flow of electricity.

After absorbing the dye, the plates are placed to dry and bond. The bottom plate is placed in a hood (conductive side up) so that the counter electrode in the form of the thin carbon soot or platinum paste may be applied. The cells are sprayed so that an even coating is achieved. This process is repeated until the total number of desired cells is obtained. The individual pieces of glass are now ready to be combined. The electrolyte solution is then placed on the dyed side of the plate, enough to saturate the surface. The two plates are sandwiched together (conductive sides touching) and secured with binder clips. The cells are now ready to be tested and is presented in Figure 5.

\subsection{Preparation of Electrolyte Solution}

The electrolyte solution consist of three different materials that we used in our research which is pure Iodine, Potassium Iodide and Ethylene glycol. We got about $0.1269 \mathrm{~g}$ of pure Iodine and $0.83 \mathrm{~g}$ of Potassium Iodide and we put both in $10 \mathrm{ml}$ of Ethylene glycol.

\subsection{Testing the Cell}

Once preparation of the positive and negative electrodes is completed, 1 - 2 drops of electrolyte are placed on 


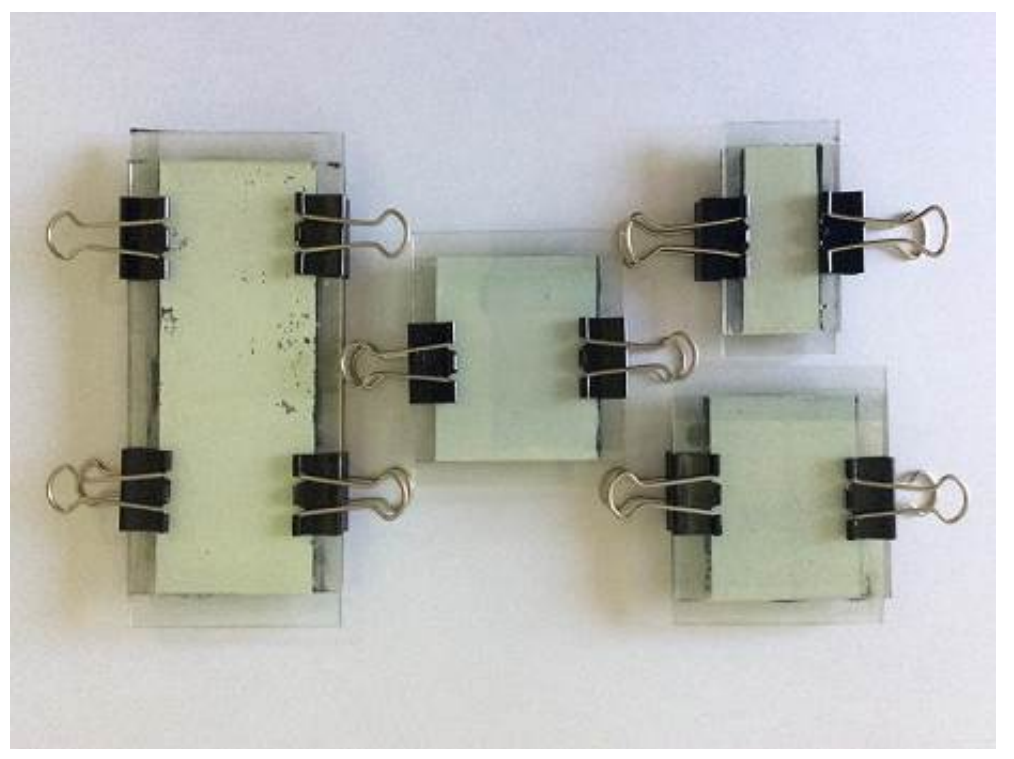

Figure 5. Completed solar cell.

the negative electrode and the two FTO plates are sandwiched together. The sandwiching of the two plates is offset so that each one has a small portion exposed so that an alligator clamp can be attached; the negative clamp goes on the $\mathrm{TiO}_{2}$ positive Sensitizer plate and the positive clamp goes on the counter electrode plate as shown in Figure 6 . The cell to be tested is held in place $15 \mathrm{~cm}$ directly below a standard lamp. Our tests were carried out by use of a multi-meter that measures both voltage and current at separate times.

\section{Results and Discussion}

Thus far in the research, the variables examined have been the sensitizing dye and the size of the conductive glass. The conductive glass used in all the cells is Fluorine Tin Oxide (FTO) glass. Moreover the Nano crystalline matrix has been Titanium dioxide $\left(\mathrm{TiO}_{2}\right)$ throughout. An outline of our variables is displayed in Table 1 .

Our most efficient reproducible data was achieved in the second trial. The cell produced a potential of $\sim 140$ $\mathrm{mV}$. The highest potential and current readings have been recorded while using Fluorine Tin Oxide (FTO) as the negative and positive plates. The readings carried out indoors under a lamp emitting all wavelengths in the visible spectrum were not found to provide steady/consistent data due to substantial heating of the cell. Test results from different cells varied greatly, even within a series. This makes it very obvious that variability exists in one of the factors, most likely the electrolyte mediator. The most probable reason for this observation is that the electrolyte is evaporating out from between the two plates due to the high temperatures under the lamp. Using a filter helps greatly with the heat, but the electrolyte still seems to undergo degradation over time with the exposure to the light.

\section{Conclusions}

One of the emerging problems in durability of the solar cells is the nature of the electrolyte. The liquid electrolyte can undergo evaporation, leaking, charge separation/recombination at the $\mathrm{TiO}_{2} /$ electrolyte interface or degradation. There may be a back-reaction that takes place between the conduction-band electrons from the excited sensitizer and the oxidized dye molecules themselves, or with the oxidized electrolyte species $\left(\mathrm{I}_{3}^{-}\right)$. The latter recombination process is:

$$
\mathrm{I}_{3}^{-}+2 e_{c b} \rightarrow 3 \mathrm{I}^{-}
$$

These processes have been a concern for other researchers producing $\mathrm{TiO}_{2}$ based solar cells. Literature reviews would have to be conducted to examine how this recombination process could be stopped or lessened. The use of a filter has also proven to lend a significant hand in decreasing the heat reaching the cell. It is also 


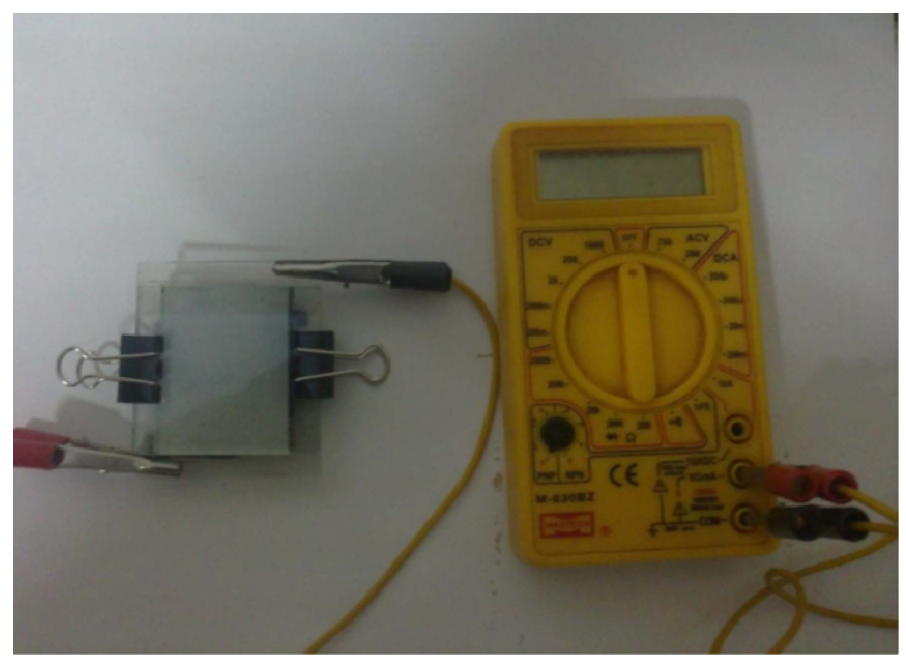

Figure 6. Testing the cell.

Table 1. Variables tested.

\begin{tabular}{cccc}
\hline S. No. & Size of Glass & Dye & Voltage obtain \\
\hline $\mathbf{1}$ & 4 (inches) & Strawberry & $\sim 80(\mathrm{mv})$ \\
$\mathbf{2}$ & 2 (inches) & Strawberry & $\sim 140(\mathrm{mv})$ \\
$\mathbf{3}$ & 2 (inches) & Turmeric powder & $\sim 40(\mathrm{mv})$ \\
$\mathbf{4}$ & 1 (inches) & Strawberry jam & $\sim 30(\mathrm{mv})$ \\
\hline
\end{tabular}

very clear that we must obtain a more realistic lamp for the environment to mimic the true full solar spectrum. Only then will we be able to see the real life practicality of the cells.

Incorporating what we have seen with our plans for the future, we feel that there are many things we may try in order to improve our results and provide insight into their nature. We are also looking into the use of quantum dots to replace our dye. Quantum dots may be manipulated to absorb a specific wavelength of light. Their absorption exists in a direct relationship with their size. If able to make set wavelengths for absorption, the cells could be arranged in series to collect energy from a variety of areas in the spectrum. Future research will involve the incorporation of quantum dots instead of the organic dye as a sensitizer. Quantum dots have the advantages of providing tunable band gaps and the ability to absorb specific wavelength, including UV light, from the solar spectrum. We also intend to explore different sealants and solid electrolytes such as conductive polymers to prevent the electrolyte evaporation.

\section{References}

[1] O’Regan, B. and Grätzel, M. (1991) A Low-Cost, High-Efficientcy Solar-Cell Based on Dye Sensitized Colloidal TiO 2 Films. Nature, 353, 737-740.

[2] Ito, S., Murakami, T.N., Comte, P., Liska, P., Grätzel, C., Nazeeruddin, M.K. and Grätzel, M. (2008) Fabrication of Thin Film Dye Sensitized Solar Cells with Solar to Electric Power Conversion Efficiency over 10\%. Thin Solid Films, 516, 4613-4619.

[3] Zeng, W., Cao, Y., Bai, Y., Wang, Y., Shi, Y., Zhang, M., Wang, F., Pan, C. and Wang, P. (2010) Efficient Dye-Sensitized Solar Cells with an Organic Photosensitizer Ferturing Orderly Conjugated Ethylene Dioxythiophene and Dithienosilole Blocks. Chemistry of Materials, 22, 1915-1925. http://dx.doi.org/10.1021/cm9036988

[4] Hardin, B.E., Yum, J.-H., Hoke, E.T., Jun, Y.C., Pechy, P., Torres, T., Brongersma, M.L., Nazeeruddin, M.K., Graetzel, M. and McGehee, M.D. (2010) High Excitation Transfer Efficiency from Energy Relay Dyes in Dye-Sensitized Solar Cells. Nano Letters, 10, 3077-3083.

[5] Campbell, W.M., Jolley, K.W., Wagner, P., Wagner, K., Walsh, P.J., Gordon, K.C., Schmidt Mende, L., Nazeeruddin, M.K., Wang, Q., Grätzel, M. and Officer, D.L. (2007) 
[6] Konno, A., Kumara, G.R.A. and Kaneko, S. (2007) Solid-State Solar Cells Sensitized with Indoline Dye. Chemistry Letters, 36, 716-717.

[7] Yu, Z., Li, D., Qin, D., Sun, H., Zhang, Y., Luo, Y. and Meng, Q. (2009) Research and Development of Dye-Sensitized Solar Cells. Materials China, 28, 7-15.

[8] Qin, Q., Tao, J. and Yang, Y. (2010) Preparation and Characterization of Polyaniline Film on Stainless Steel by Electrochemical Polymerization as a Counter Electrode of DSSC. Synthetic Metals, 160, 1167-1172.

[9] Meng, S., Ren, J. and Kaxiras, E. (2008) Natural Dyes Adsorbed on $\mathrm{TiO}_{2}$ Nanowire for Photovoltaic Applicaitons: Enhanced Light Absorption and Ultrafast Electron Injection. Nano Letters, 8, 3266-3272. 